\title{
"ELEMENTOS DE ÁLGEBRA" DE CRISTIANO BENEDITO OTTONNI: ANÁLISE DE UM INSTRUMENTO DIDÁTICO DO SÉCULO XIX
}

\author{
Elaine Cristina Luiz \\ Samira Saad Pulchério Lancillotti
}

\section{RESUMO}

O presente estudo tem por objetivo estabelecer a análise de um compêndio de Álgebra, a saber, "Elementos de Álgebra", de Cristiano Benedito Ottoni, adotado nos Programas de Ensino do Colégio Pedro II, no período de 1856-1870. A análise é norteada pela categoria organização do trabalho didático, que permite apreender, historicamente, o papel dos instrumentos didáticos no interior das atividades desenvolvidas em âmbito escolar e apontar as funções assumidas por estes compêndios na relação educativa. Elegemos a temática Teoria dos Logaritmos como vetor para observar em que medida a atividade didática foi objetivada neste instrumento de trabalho. A análise nos permitiu apreender a base do ensino dessa disciplina no Brasil e indicar que os instrumentos didáticos utilizados para o ensino de álgebra, no século XIX, traziam um conteúdo que exigia do professor maior domínio deste campo de conhecimento e permitiam oferecer uma formação mais sólida aos educandos; contudo, no decurso do tempo, o trabalho didático foi sendo progressivamente objetivado e simplificado com vistas a favorecer a disseminação do ensino escolar.

Palavras-chave: Organização do Trabalho Didático; Cristiano Benedito Ottoni; Compêndio de Álgebra; Colégio Pedro II.

\section{"ELEMENTOS DE ÁLGEBRA" BY CRISTIANO BENEDITO OTTONI: ANALYSIS OF A DIDACTIC TOOL IN THE 19TH CENTURY}

\begin{abstract}
The present study has as goal to stablish the analysis of a compendium of algebra, "Elementos de Álgebra" by Cristiano Benedito Ottoni, used in the teaching programs of Pedro II school during the period of 1856-1870. The analysis is guided through the category didactic work organization which allows to learn historically, the role of didactic tools within the activities developed in school scope, and to point the functions adopted by these compendiums in the educational relation. We elected the theme Logarithm Theory as the carrier to learn to which the didactic activity was objectified in this working tool. The analysis allowed us to grasp the basis of teaching in this discipline in Brazil, and to indicate that the didactic tools used to teach algebra in the 19th century, brought a content that demanded from the teacher higher control of this field of knowledge, and enabled to offer more consistent education to the students. However, in the course of time, the didactic work was progressively objectified and simplified in view of favoring the dissemination of school teaching.
\end{abstract}

Key words: Didactic work organization. Cristiano Benedito Ottoni. Algebra Compendiums. Pedro II School. 


\section{INTRODUÇÃO}

As inúmeras leituras acerca das origens e formas históricas de organização do trabalho didático na escola moderna, do papel dos instrumentos didáticos como elementos centrais na relação educativa - caso dos compêndios e dos manuais didáticos - e de seu caráter histórico (ALVES, 2001, 2005, 2006, 2011, 2012) revelaram-nos uma lacuna que precisa ser preenchida nos estudos sobre o ensino da Matemática.

Qual o papel e a função assumidos pelos instrumentos didáticos de Matemática na relação entre o educador e o educando? Como se configuraram e em que medida transformaram-se os textos escolares de Matemática? Estas são questões que se colocam para novas investigações.

Os instrumentos didáticos de Matemática têm sido objeto de análise para inúmeros pesquisadores, particularmente na última década, entretanto não encontramos nenhum estudo que avançasse no estudo dos compêndios e manuais didáticos, enquanto instrumentos de trabalho do professor. Neste sentido trazemos, com este artigo, a análise de um compêndio de Álgebra, adotado no Colégio Pedro II, de 1856 e 1870. Trata-se do "Elementos de Álgebra", de Cristiano Benedito Ottoni, do qual tomamos a temática Teoria dos Logaritmos como vetor para a discussãoi.

O estudo toma por referência a categoria teórica organização do trabalho didático, proposta por Gilberto Luiz Alves (2005, 2006, 2012a), norteadora de estudos a respeito da relação educativa. É com base nesta referência que buscamos descrever e analisar de que maneira se configurou este texto escolar de Álgebra na formação secundária brasileira do período Imperial.

A Matemática é uma ciência construída, aperfeiçoada e organizada em teorias válidas para suprir as necessidades humanas em constante transformação. É a ciência mais aplicada em nosso cotidiano. A ciência dos números, das abstrações e do raciocínio lógico, perfaz de entendimento coerente, técnicas precisas e exatas.

Em desenvolvimento permanente, procura emular padrões e formular conjecturas capazes de estabelecer novos resultados. A Matemática é universal e impacta todas as ciências. É a ciência que possui o maior grau de generalizações, considerada capaz de desvendar a realidade mais simples como a mais complexa e indeterminada. É possível, inclusive, aplicar a análise matemática aos fenômenos políticos, sociais e principalmente aos econômicos; ou seja, a Matemática faz jus ao conceito de fundamental e universal.

A Álgebra é um dos principais ramos da Matemática, capaz de generalizar os conceitos e as operações aritméticas. O aluno que adquire o conhecimento algébrico tornase mais autônomo, domina um conhecimento que o torna capaz de resolver desde as situações mais simples e perceptíveis até as mais complexas e abstratas, daí sua importância.

$\mathrm{Na}$ educação matemática atual, o uso de incógnitas transtorna os estudantes e estabelece uma barreira no desenvolvimento escolar; um indicativo de que a base desta aprendizagem está deficiente e defasada. Considera-se que a compreensão desta problemática impõe a investigação histórica do trabalho didático e, fundamentalmente, dos instrumentos didáticos utilizados para o ensino de álgebra, buscando analisá-los em processo, tentando apreender seu papel no esvaziamento desta formação.

A análise do Compêndio de Álgebra de Cristiano Benedito Ottoni vem no sentido de contribuir com a compreensão deste movimento e é estabelecida, como já se anunciou, sob a perspectiva da organização do trabalho didático, ferramenta conceitual formulada por Alves, (2005), para quem: 
No plano mais genérico e abstrato, qualquer forma histórica de organização do trabalho didático envolve, sistematicamente, três aspectos: a) ela é, sempre, uma relação educativa que coloca, frente a frente, uma forma histórica de educador, de um lado, e uma forma histórica de educando (s), de outro; b) realiza-se com a mediação de recursos didáticos, envolvendo os procedimentos técnico-pedagógicos do educador, as tecnologias educacionais pertinentes e os conteúdos programados para servir ao processo de transmissão do conhecimento; c) e implica um espaço físico com características peculiares, onde ocorre. (p. 10-11, grifos do autor).

Ainda, segundo o autor, a categoria em questão é formulada no interior da ciência da história, subordinada a outras categorias centrais do pensamento marxista, como: trabalho e organização técnica do trabalho, portanto as implica. A partir do aprofundamento teórico nas formulações do autor, pudemos compreender que o trabalho didático é uma forma especializada de trabalho. É no veio do capitalismo que o trabalho deixou de ser artesanal e passou a ser especializado. Na medida em que foi dividido, surgiram novas ferramentas mais adequadas para cada uma das tarefas que fazem parte do processo integral de trabalho. Essas ferramentas tiveram o objetivo de facilitar o trabalho e aumentar a produção, de modo que qualquer trabalhador, mesmo sem muito domínio do processo, fosse capaz de fazê-lo. Com o passar do tempo, estes instrumentos foram se modificando, sendo "aperfeiçoados", ou seja, objetivaram mais ainda o trabalho, o que equivale a dizer que grande parte do processo foi transferido da mente do trabalhador para o instrumento, de modo que outros trabalhadores passaram a dispor deste trabalho objetivado, sendo capazes de executar as tarefas com grande facilidade, mesmo que não tenham domínio pleno do conhecimento.

Com fulcro nesta compreensão, tratamos de descrever e analisar o compêndio referido, a partir dos conteúdos de logaritmos, apontando as características marcantes da obra: sua linguagem, organização e distribuição dos temas complementares dos logaritmos, recurso aos exemplos, forma de apresentação dos tópicos, sequência didática e presença, ou ausência, de demonstrações, enfim, a didatização do conteúdo, expressa na sua simplificação e na objetivação do trabalho didático, com vistas a facilitar o uso deste texto escolar pelo professor e pelos alunos.

Antes de avançar propriamente na análise da obra, cabe fazer aqui um destaque, observamos que os autores, os quais se debruçam sobre a análise dos instrumentos didáticos, não revelam preocupação em distinguir compêndios de manuais didáticos, textos escolares ou livros didáticos, tratando-os como sinônimos.

Esta questão é objeto de preocupação dos autores de referência para esta análise, que utilizam a denominação genérica "Textos escolares" para fazer referência a um "[...] amplo espectro de obras [como manuais, antologias, dicionários, cartilhas, seletas, etc.] que, voltadas e/ou utilizadas no processo de escolarização, vão ganhando diferente forma e conteúdo, acordante com a configuração histórica em que surgem e se tornam hegemônicas". (BRITO, et. al, 2012, p. 177).

Já os compêndios, uma das modalidades de texto escolar, são instrumentos didáticos que, comparados aos manuais didáticos mais recentes, apresentam conteúdo complexo, que exige maior domínio e conhecimento especializado por parte do professor. Também não são direcionados a níveis específicos de escolarização, referem-se a uma área do conhecimento, podendo circular livremente entre os diferentes níveis de ensino, como também fora do espaço escolar (ALVES; CENTENO, 2012). 
Manuais didáticos, um outro tipo de texto escolar, são elaborados para níveis precisos de escolarização, não circulando para além da sala de aula. Têm conteúdo simplificado, fragmentação e aligeiramento de informações, ocasionando perda do grau de aprofundamento teórico; excesso de ilustrações. (ALVES; CENTENO, 2012).

Outra característica dos manuais didáticos é que o texto destinado aos alunos vem acompanhado de um manual de uso privativo do professor, com todas as respostas prontas e uma rotina que deve ser seguida, ou seja, objetiva o trabalho do professor, que "[...] se submete, incondicionalmente, às rotinas previstas no próprio instrumento de trabalho". (ALVES, 2011, p. 302). Um outro aspecto que se destaca no uso dos manuais didáticos é seu caráter excludente, que tende a afastar do trabalho educativo outras fontes de conteúdo.

Feitas estas distinções, passaremos à descrição e análise do compêndio Elementos de Álgebra, de Cristiano Benedito Ottoni, foco deste estudo.

\section{AUTOR E A OBRA}

\subsection{Cristiano Benedito Ottoni}

Cristiano Benedito Ottoni foi personagem fundamental para a organização e estruturação da Matemática escolar no Brasil por quase meio século (VALENTE, 2007). Esse fato confere relevância ao seu nome para aqueles que pretendem uma discussão histórica do ensino escolar neste campo de conhecimento. Nasceu no dia 21 de maio de 1811, na Vila do Príncipe ii, Província de Minas Gerais, e faleceu em maio de 1896, vítima da progressão da malária nas matas do Mucuri.

Além de sua importância para o ensino das Matemáticas, destaca-se sua atuação política no período Imperial, iniciada nos anos de 1830. A este respeito, Miorim observa: "[...] assumiu sua posição de liberal, democrata, republicano, envolvendo-se, com intensidades variadas, em todos os eventos de seu tempo" (MIORIM, 2011, p. 6).

Em 1834, aos vinte e três anos, foi nomeado lente substituto da Academia da Marinha por meio de concurso. A partir de 1844, passou à condição de lente catedrático de Matemática, lecionando as disciplinas de Aritmética, Álgebra, Trigonometria e Geometria, permanecendo como professor por vinte e um anos (MIORIM, 2011).

Aos vinte e quatro anos, em 1835, foi eleito Deputado à Assembleia do Rio de Janeiro em sua primeira legislatura e teve assento no Parlamento durante várias legislaturas (VALENTE, 2007, p. 148).

Capitão-Tenente da Marinha, engenheiro, professor jubilado de Matemática em 1854, Senador do Império e da República, signatário do Manifesto Republicano, “[...] professor honorário da Academia de Bellas-Artes, do conselho do ex-imperador, dignitário da ordem do Cruzeiro ${ }^{\mathrm{iii}}$, oficial da de S. Leopoldo, da Bélgica ${ }^{\mathrm{iv}}$ [...]" (BLAKE, 1883, p. 106), C. Ottoni deixou o magistério em 1855 para assumir a direção da Companhia da Estrada de Ferro D. Pedro II, onde mais tarde tornou-se presidente, permanecendo até dezembro de 1865, quando pediu exoneração do cargo.

Para Valente: "Cristiano Benedito Ottoni é exemplo singular de autor que transitou do ensino técnico-militar para os currículos de formação clássico-literária" (2007, p. 131). Além disso, suas obras foram referência de ensino por cerca de meio século. Vechia e Lorenz reforçam esta consideração ao afirmarem: "Se houve um autor cujos livros didáticos predominaram no ensino da Matemática no Colégio Pedro II, no século XIX, foi Cristiano Benedito Ottoni”" (2004, p. 57). 
Foi pioneiro ao conceber e construir, com grande competência, uma obra técnica portentosa e exata. À época em que a engenharia nacional engatinhava, fez subir os trilhos da Serra do Mar em direção a Minas Gerais e São Paulo; por força desta atividade, é considerado, no Brasil, o "Pai das estradas de ferro" (MIORIM, 2011, p. 10).

Com respeito à sua obra didática, o próprio autor considera: “[...] foram bem aceitos e adotados em quase todos os estabelecimentos de instrução secundária e superior" (OTTONI, 1983, p. 63). A carreira de C. Ottoni como escritor de compêndios iniciou em meados de 1844, quando assumira a cadeira de lente catedrático de Matemática na Academia da Marinha.

Enquanto aluno da Academia da Marinha, C. Ottoni estudava a partir dos textos de Bézout, o que se justifica pelo fato de que:

Os Estatutos da Real Academia Militar, prescritos pelo Decreto de $1^{\circ}$ de abril de 1796, enfatizavam que as lições deveriam ser dadas segundo os 'compêndios' utilizados naquele momento [...]. Os professores deveriam seguir os compêndios indicados, não lhes sendo permitido utilizar outros ou fazer de outra forma. Um autor dos Compêndios, embora não mencionado nos Estatutos, era Étienne Bézout. (MIORIM, 2011, p. 7).

Lagrange, membro do comitê Conseil d'Instruction Publique ${ }^{\mathrm{v}}$, em uma das deliberações a respeito da supervisão dos padrões de ensino na França e na tarefa de escolher o melhor livro-texto para cada disciplina, propõe "[...] os volumes de Bézout como os melhores livros didáticos a serem usados pelos alunos." (SCHUBRING, 2003, p. 97).

Como lente substituto na Academia da Marinha, C. Ottoni ensinava "[...] pelos livros do velho Bezout, notáveis no seu tempo, mas ora imprestáveis, em vista dos progressos da ciência". (OTTONI, 1983, p. 62).

Inspiradas no modelo de instrução francesa, as instituições brasileiras de instrução superior, como a Academia Real Militar, e de Ensino Secundário, como o Colégio Pedro II, adotaram, quase que totalmente, os livros-textos franceses, devido à falta de livros nacionais, ocasionando "um grande esforço inicial" de traduzir e compilar os autores franceses (SOARES, 2011). Grande parte dessa produção vinha das Matemáticas, "[...] desdobradas em Aritmética, Geometria, Álgebra exemplificam essa produção modelada em obras européias, lembrando ainda que os programas curriculares eram originários e 'traduzidos', em sua maioria, da França." (BITTENCOURT, 2004, p. 482).

As primeiras obras didáticas nacionais de Matemática começaram a surgir na década de 1830 (SOARES, 2011). São os compêndios que, mesmo sendo escritos por autores brasileiros, continham conteúdos extraídos de obras francesas. É o caso da produção didática de C. Ottoni.

Ambicionando fundar uma reputação científica regendo a cadeira do $1^{\circ}$ ano da Academia da Marinha, "[...] insatisfeito com o ensino de Matemática na instituição" (LORENZ; VECHIA, 2004, p. 58), lecionando Aritmética, Álgebra e Geometria, C. Ottoni empreendeu a escrita de "[... novos compêndios para meu $1^{\circ}$ ano, e neles trabalhei desde 1849 até 1853 ou 1854" (OTTONI, 1983, p. 62).

Do conhecimento matemático, o que o satisfazia eram as obras de Aritmética e Álgebra de Bourdon e a Geometria de Vincent, que Ottoni compilou e adaptou, segundo suas necessidades, conforme explicita o seguinte excerto: "[...] modificando a exposição e os métodos no sentido de minhas observações no tirocínio do magistério, empreendi escrever novos compêndios para o meu $1^{\circ}$ ano [...]" (OTTONI, 1983, p. 62). 
Em suas memórias, declara:

Prestei, sem dúvida alguma, bom serviço ao ensino das Matemáticas Elementares; mas não me ficou orgulho de Autor: já disse que compilei Bourdon e Vincent. Entretanto, não exageremos na modéstia: quem confrontar a compilação com os escritores compilados há de encontrar alguma diferença de exposição e método, que me parecem melhoramentos. [...] Eu era entusiasta dos autores a que me acostei; e de Vincent era e sou profundo admirador. Aquela abundância na dedução de cada teoria, aquela lucidez lógica me causaram estremecimento de prazer. (OTTONI, 1983, p. $62)$.

Eclético na habilidade que se refere à produção de textos, C. Ottoni não se ateve somente à escrita de compêndios de Matemática, possuindo uma vasta bibliografia, que perpassa textos técnicos, como "As Máchinas a Vapor", de 1846 e "O Estado Actual da Estrada de Ferro D. Pedro II", de 1859; textos biográficos, de que é exemplo a "Biographia de Theophio Ottoni"vi , 1870; além de textos de cunho político, sobre questões candentes de seu tempo, como é o caso de "A emancipação dos escravos", 1871, "Questão religiosa" e "A liberdade de cultos: cartas escriptas do Rio de Janeiro para um jornal de província", de 1877.

Relevante para este trabalho é o compêndio "Elementos de Álgebra", aqui tomado como objeto para análise mais detida.

C. Ottoni não ambicionava auferir ganhos com seus compêndios, mas tamanho foi o sucesso de suas obras que relata, em suas memórias, a venda de seis mil exemplares de Aritmética em duas edições, cinco mil e seiscentos exemplares de Álgebra em duas edições e sete mil exemplares de Geometria em três edições. Ao final de sua "Autobiografia", em notas de correção ou acrescentando informações relevantes ao seu texto, declara a venda de nove mil exemplares de Álgebra e outros nove mil de Geometria que, segundo o próprio autor: "[...] deram-me pois os meus compêndios uma remuneração pecuniária de cerca de 60 contos de réis líquidos, muito inferior ao que vale a reputação que me criaram: não creio que haja nestas palavras imodéstia" (1983, Nota E, p. 253). De fato a reputação de C. Ottoni percorreu várias instituições de Ensino Superior e Secundário no Brasil, sendo "[...] o primeiro autor de livros didáticos [das matemáticas] de aceitação e adoção nacional" (VALENTE, 2000, p. 205).

Além de lhe granjearem enorme prestígio, as obras didáticas de C. Ottoni também serviram de base para outros autores de livros de Matemática, como por exemplo, José de Abreu Medeiros, Bacharel em Ciências Sociais e Jurídicas que, ainda estudante, publicou, em 1878, em São Paulo, o livro "Geometria Plana", composto de "[...] Theoremas e corollários de Geometria Plana, extrahidos do compendio do conselheiro C. Ottoni [...]". (BLAKE, 1883, v 4, p. 266). Outro autor de livros didático que compilou C. Ottoni foi Jeronymo Pereira de Lima Campos, lente jubilado da Academia da Marinha, onde obteve sua formação inicial, vice-almirante da mesma Academia, cavaleiro da Ordem de São Bento, deputado da Assembleia do Rio de Janeiro, escreveu "Pontos de Geometria para provas escriptas nos exames da instrução pública da corte". (BLAKE, 1883, v 3, p. 306).

Os compêndios de C. Ottoni (Aritmética, Álgebra, Geometria e Trigonometria) não circularam somente na Academia da Marinha, mas principalmente no Colégio Pedro II, "[...] o padrão a ser emulado pelos seus congêneres" (VECHIA; LORENZ, 2004, p. 54), sendo indicados nos Programas de Ensino por quase quatro décadas, de 1856 a 1893. Salientamos 
que o compêndio de Álgebra esteve em uso de 1856 a 1870. Outras fontes revelam que, em alguns Colégios, os mesmos foram adotados por mais tempo; é o caso do Atheneu Sergipense, que no ano de 1903, adotou compêndios de C. Ottoni para os estudos de Geometria e Trigonometria (ALVES 2008).

Com respeito à substituição de suas obras no Colégio Pedro II, Valente alerta:

A diferença dos textos didáticos que passaram a ser utilizados posteriormente aos de Ottoni está em sua forma didática. As obras de Ottoni seguem a estruturação clássica: apresentação teórica seguida de exemplo numérico. Não há exercícios para os alunos. Os textos que substituem Ottoni passam a ser escritos visando já ao uso pelos alunos. Incluem exercícios gradativos, exercícios com resposta final, exercícios sem resposta, resumos, etc. Esse é o caso de textos de Aritmética e Álgebra do professor Adelino Serrasqueiro e da Geometria do professor Timótheo Pereira. O primeiro adotado, pelo Pedro II, desde 1891 até 1923, pela sua Álgebra, e o segundo, a partir de 1898, em substituição à Geometria de Ottoni [...] (2000, p. 204-205. Grifo nosso).

A característica didática dos textos de Ottoni é de interesse marcante para este trabalho, que busca contribuir com o esforço acadêmico de apreender as mudanças dos textos escolares no decurso do movimento histórico, neste sentido, buscaremos, em sequência, avançar na descrição e análise de um dos compêndios escritos por C. Ottoni.

\subsection{O Compêndio "Elementos de Álgebra"}

A obra "Elementos de Álgebra" foi adotada no Colégio Pedro II de 1856 a 1870 (VECHIA e LORENZ, 1998; BELTRAME, 2000). O exemplar analisado é parte da quarta edição, publicada em 1879, em versão "Correcta e Augmentada", conforme consta da contracapa.

A primeira edição do "Elementos de Álgebra", compilada de Bourdon, foi publicada em $1852^{\text {vii }}$. No prefácio, o autor faz constar que, com este livro, avança no objetivo de "reformar o ensino do primeiro ano de Matemáticas da Academia de Marinha" (VALENTE, 2007, p. 151) e ainda justifica a compilação da obra de Bourdon:

Pratiquei com a Álgebra o mesmo que com a Aritmética: escolhi dentre os clássicos de melhor nota as obras de Bourdon, para cingir-me ao seu método, compilando as doutrinas, sem me limitar a uma simples e fiel tradução. Conheço a opinião de grande peso, que daria a preferência ao tratado de Álgebra de Lefebvre de Fourcy, mas, além de que não lhe julgo inferior o que adotei, acresce que era vantajoso conservar uniformidade dos métodos e doutrinas e, para isso, é de importância estudar o cálculo aritmético e o cálculo algébrico, segundo as vistas e o espírito de um mesmo autor. (OTTONI, 1852, apud VALENTE, 2007, p. 152).

C. Ottoni limitou-se a compilar o conteúdo de Álgebra que considerava o mais pertinente para o primeiro ano da Academia da Marinha. Tal limitação foi responsável pela constituição da Álgebra a ser ensinada nas Escolas Secundárias brasileiras. A este respeito, 
Valente indica: “[...] Ottoni que define a Álgebra secundária a ser ensinada posteriormente nos colégios e liceus". (2007, p. 153).

Uma possível justificativa para o fato de a Álgebra de C. Ottoni ter se tornado referência para o Ensino Secundário brasileiro é a carência de obras nacionais, sendo que a maioria dos compêndios adotados no Brasil era de origem francesa. Se C. Ottoni compilou autores franceses que estavam em destaque no momento nas escolas francesas, era conveniente optar por uma obra nacional, traduzida, que facilitaria o acesso a um maior contingente de professores e alunos, uma vez que estava vertida na língua vernácula. Logo, os mesmos métodos de ensino adotados na França circulavam no Brasil, principalmente no Colégio Pedro II, por meio dos compêndios de C. Ottoni.

Passaremos, em sequência, à descrição do exemplar analisado. Conforme é possível observar na contracapa (Figura 1), o compêndio era adotado tanto nos estabelecimentos de Instrução Superior como nos de Secundária, do Império.

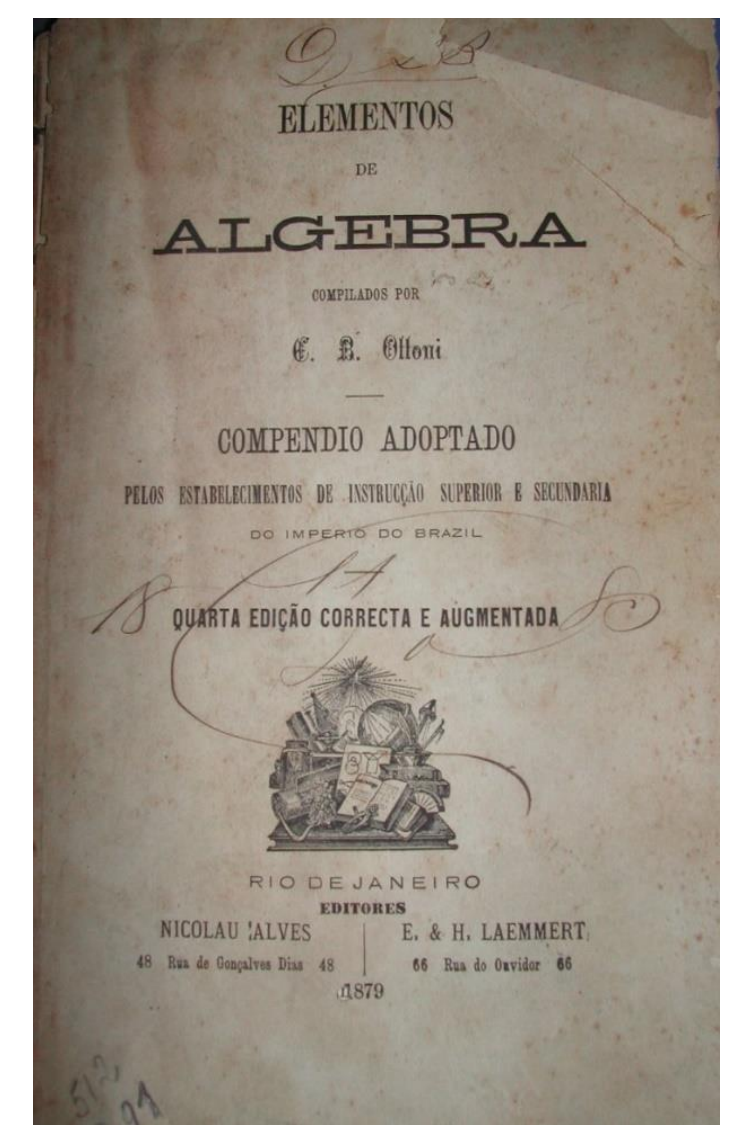

Figura 1: Folha de Rosto do Elementos de Álgebra. Fonte: OTTONI (1879)

A possibilidade de uso em distintos níveis de ensino é um diferencial que se observa entre compêndios e manuais didáticos, conforme já sinalizamos anteriormente.

A obra encontra-se dividida em seis capítulos.

Para a análise, tomaremos, como vetor, o conteúdo "Theoria dos Logarithmos", que aparece no último capítulo da obra, conforme indica o índice, sendo, por decorrência, o último conteúdo a ser ensinado. Porém há de se destacar que todo o conteúdo de base, necessário ao ensino dos logaritmos encontra-se nos itens anteriores, o que reforça a 
consideração feita por Valente de que, "[...] Ottoni tem uma preocupação de continuidade didática". (2007, p. 152).

$\mathrm{Na}$ Introdução, C. Ottoni explicita claramente a importância da Álgebra e os elementos essenciais que a compõem:

1. Álgebra é a parte das mathemáticas em que se empregão signaes próprios para abreviar e generalizar os raciocínios que exige a solução das questões relativas aos números. Há duas espécies de questões mui distinctas, a saber: $\mathrm{O}$ theorema, que tem por objeto demonstrar certas propriedades de que gozão números dados; O problema, cujo fim é determinar o valor de certos números, por meio de outros conhecidos, com os quaes conservão aquelles relações definidas pelo enunciado da questão. (OTTONI, 1879, p. 5, grifos do autor).

Afirma ainda que é indispensável ao estudante "[...] compreender e desenvolver os fecundos recursos que a Álgebra oferece para a resolução de grande número de questões" (OTTONI, 1879, p. 7).

Em todo o texto, o autor recorre à sua Arithmética, relembrando as propriedades numéricas com aplicação na Álgebra, preocupa-se em deixar claro que muitas propriedades aritméticas têm aplicação na Álgebra, ou seja, os mesmos princípios matemáticos, como a divisão, por exemplo. Os conceitos de divisão numérica ou aritmética e divisão algébrica são os mesmos, o que muda é a maneira de escrever; na Aritmética, usamos números; na Álgebra, usamos letras e números.

Atendo-nos ao conteúdo escolhido para análise, saltamos para o Capítulo VI, intitulado: " Applicação dos Princípios da Álgebra às Progressões e Logaríthmos", no qual o autor afirma: "[...] este capítulo completa os conhecimentos de Álgebra absolutamente indispensaveis ao estudo da Trigonometria e da Applicação da Álgebra à Geometria" (OTTONI, 1879, p. 186, grifos do autor).

C. Ottoni inicia o capítulo com as progressões, refere-se às aritméticas como progressões por diferenças e as geométricas como progressões por quocientes.

Talvez quisesse chamar a atenção ao fato de que os logaritmos não são aplicáveis apenas nas exponenciais, mas também nas progressões, principalmente nas geométricas, ou por quociente, conforme determina o autor, na busca, por exemplo, da quantidade de termos.

Cada explicação é colocada em um tópico, representada por um número que, ao longo de toda a obra, é sequencial. Nem todos os tópicos explicativos são seguidos de exemplos numéricos. Em muitos casos, C. Ottoni restringe-se somente ao exemplo algébrico, o que implica o domínio teórico do professor que faz uso de seu compêndio acerca do tema abordado. Raros os casos em que aplica à teoria um exemplo numérico.

Uma outra característica que se evidencia da análise é que C. Ottoni não propõe exercícios, em nenhum ponto da obra, deixando tal tarefa a cargo do professor; também os exemplos numéricos devem ser propostos, independentemente, pelos professores que se utilizam de seu compêndio. A obra não denota qualquer preocupação do autor em objetivar estas atividades, de modo que, para extrair de seu livro didático todo o conteúdo proposto, a atividade docente é amplamente solicitada, o que implicaria um grau de conhecimento mais profundo.

Vemos aqui um possível motivo pelo qual as obras de C. Ottoni foram substituídas, pois, de acordo com as orientações da Instrução de 27 de outubro de 1880: “[...] convém que se não absorva todo o tempo letivo só em explicações e lições dos diversos pontos do 
programa, para que tenham os alunos ocasião de fazer muitos exercícios e possa o professor interrogá-los a miúdo" (VALENTE, 2007, p. 174).

C. Ottoni também não expõe todas as propriedades dos logaritmos. Reporta-se àquelas que, a seu modo de ver, seriam as mais importantes, deixando aos docentes a dedução das demais. Seu texto é destituído de ilustrações, com um discurso contínuo organizado por tópicos numerados, articulando início, meio e fim dos conteúdos, porém de maneira complexa.

A linguagem adotada pelo autor no instrumento didático é de caráter mais científico, compreensível para iniciados e de difícil acesso para aqueles que não têm domínio dos fundamentos da Álgebra elementar.

Sempre que julga necessário, o autor retoma itens anteriores ou mesmo problemas propostos anteriormente, a título de exemplo trazemos, na Figura 2, a imagem da página 207, na qual o problema apresentado, de número 194, faz referência a um problema anterior; o de número 180, para explicar que, com a teoria dos logaritmos, a resolução passa a ser possível.

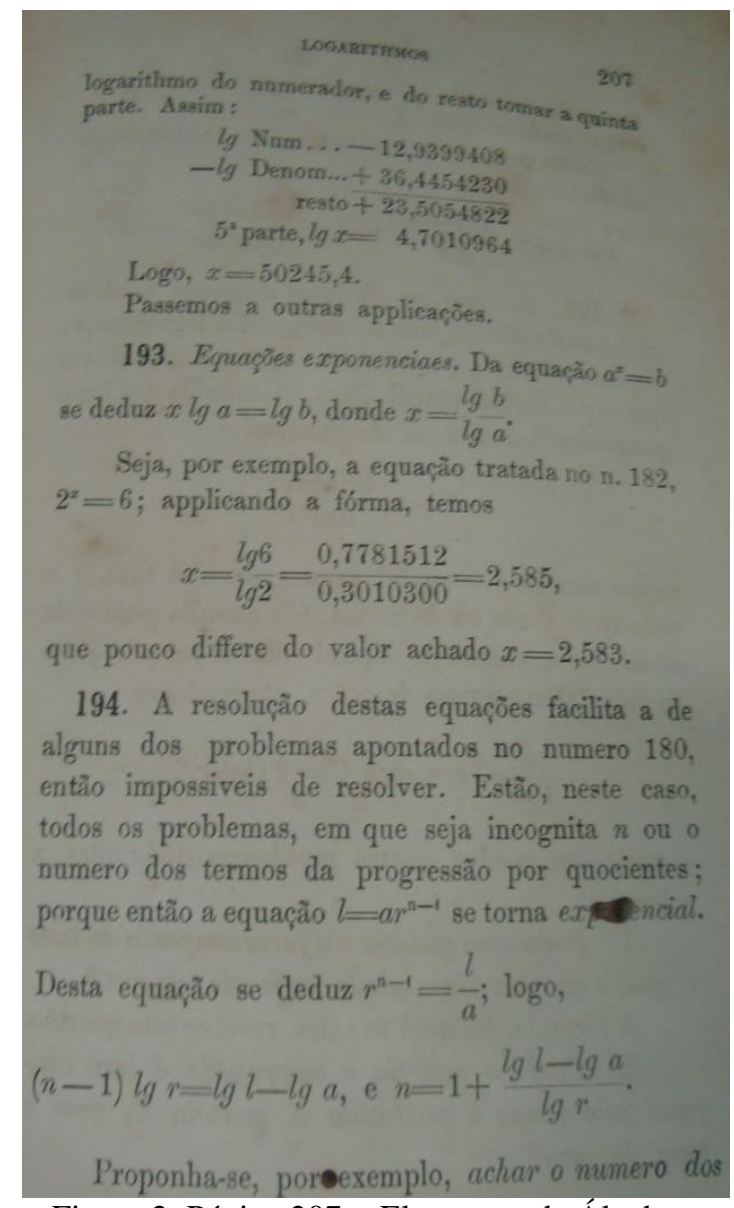

Figura 2: Página 207 - Elementos de Álgebra. Fonte: OTTONI (1879, p. 207)

Logo em seguida, propõe outro conteúdo de aplicabilidade dos logaritmos. Trata-se de juros compostos. Novamente apresenta o conteúdo com exemplos algébricos para chegar às fórmulas de juros compostos e de desconto composto, aí sim propõe um exemplo numérico para calcular o tempo de aplicação de uma quantia cuja solução dá-se pela aplicação de logaritmos. Ao final do capítulo, C. Ottoni propõe dois exemplos de juros 
compostos resolvidos, um deles inclusive envolvendo progressão por quociente e aplicação de logaritmos.

Observamos que o autor tem a preocupação de envolver várias aprendizagens ao mesmo tempo e que, em muitos casos, os conteúdos são interdependentes, um conceito pressupõe outro para resolver determinadas questões. Esta ordem e dependência são típicas do formalismo matemático.

$\mathrm{O}$ autor deixa claro, em suas memórias, que escrevia seus compêndios baseando-se nas suas experiências como professor; logo seus compêndios traziam objetivada a sua experiência docente. Neste sentido, era ferramenta de trabalho que pretendia colocar a serviço de outros professores a sua vivência prática.

A nosso juízo, o texto de C. Ottoni é sucinto, complexo e denso, para o entendimento independente do aluno; traz poucos exemplos numéricos e não oferece nenhum exercício. Atribui ao professor as tarefas de elaborar mais exemplos, inclusive os numéricos, além dos exercícios para os alunos. Nesse sentido, ainda exige do professor que se utiliza de seu compêndio, um amplo domínio do conteúdo a ser ensinado. Estas questões ficam mais claras quando observamos, por exemplo, a explicação de C. Ottoni para a multiplicação e divisão dos logaritmos, conforme é possível observar na Figura 3.

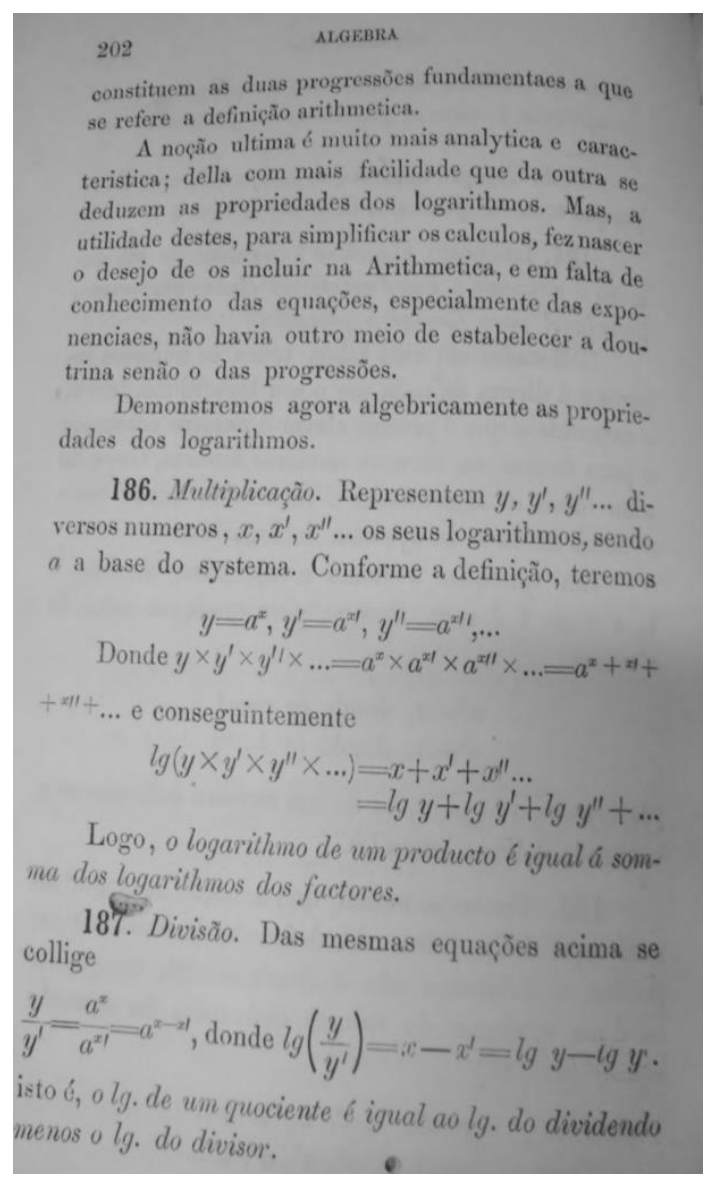

Figura 3: Multiplicação e Divisão Logarítmica Fonte: OTTONI (1879, p. 202) 
Como vemos, não há exemplos numéricos que facilitem a compreensão, ou a proposição de exercícios. Estas tarefas, como já afirmamos, devem ser propostas pelos professores.

Ao final da obra, C. Ottoni escreve um "Appendice". Nele encontramos várias "Notas" a respeito dos conteúdos explicados anteriormente, bem como a demonstração de "Theoremas", "Corollarios" e "Lemmas" inexistentes no corpo de todo o texto.

$\mathrm{Na}$ Nota IX, encontramos a demonstração de vários "Lemmas" referentes a funções exponenciais e nenhuma que diz respeito aos logaritmos.

Ao que tudo indica, essas "Notas" são explicações complementares aos conteúdos apresentados no restante da obra. É possível que C. Ottoni quisesse apresentar um texto conciso, não inserindo essa complementação no corpo da obra para não sobrecarregá-la, ou, talvez, essas notas tenham sido acrescidas posteriormente para facilitar aos usuários o trânsito pela obra. Lembremo-nos de que se trata de exemplar da quarta edição, "Correcta e Augmentada", conforme consta da folha de rosto, infelizmente não tivemos acesso à primeira edição, para observarmos as mudanças introduzidas. De todo modo, notamos que esta característica é muito comum em exposições de Matemática.

Vejamos, ainda, como propõe a aplicação dos logaritmos aos problemas de juros compostos, nas Figuras 4 e 5.

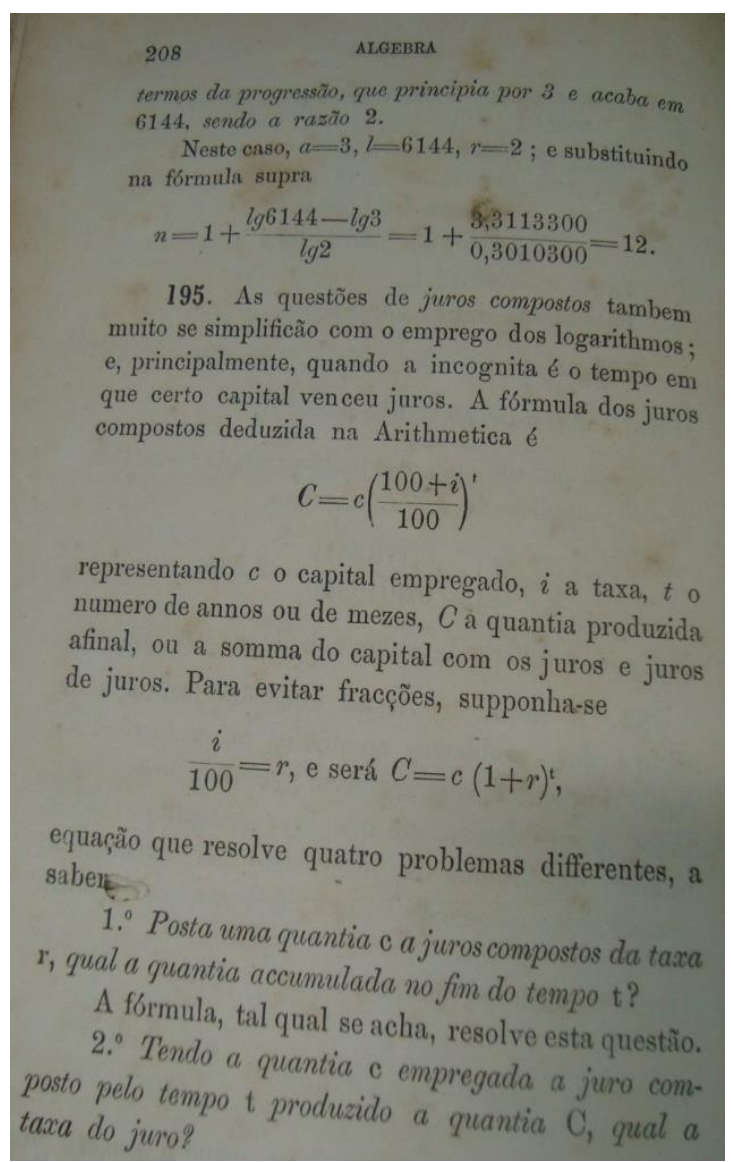

Figura 4 Juros Compostos

Fonte: OTTONI (1879, p. 208) 


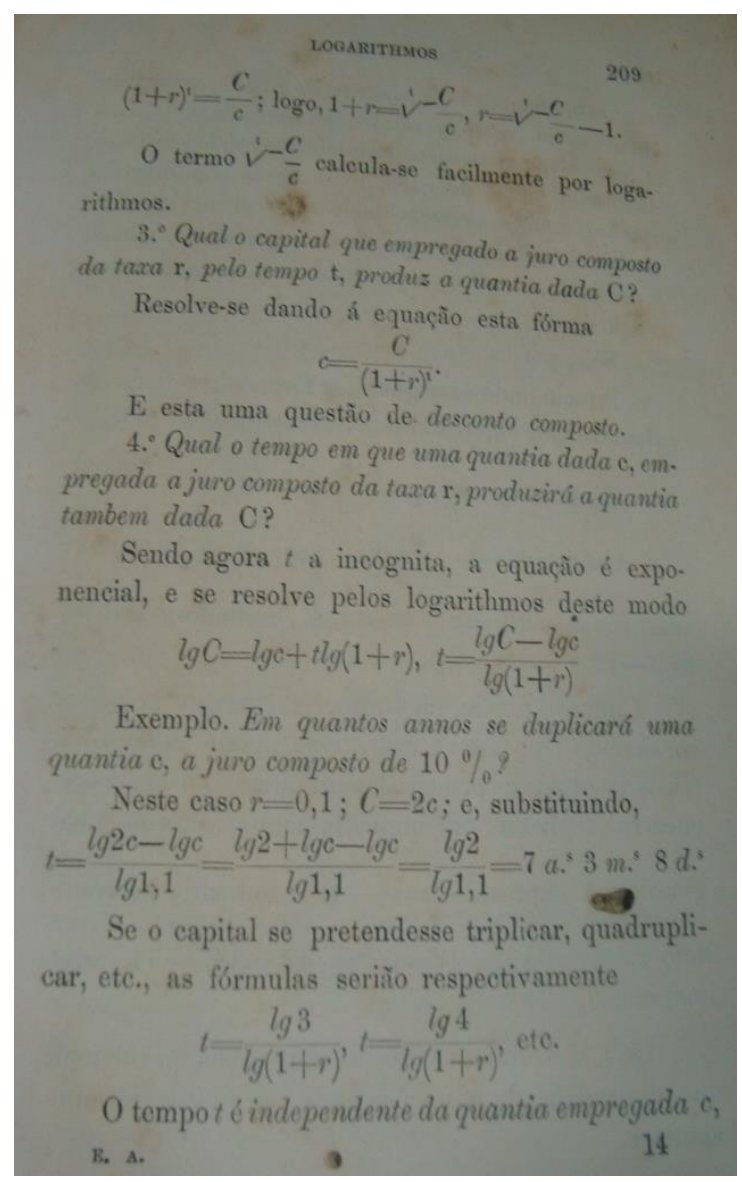

Figura 5: Juros Compostos - Continuação.

Fonte: OTTONI (1879, p. 209)

Observamos que C. Ottoni apresenta todas as fórmulas de cálculo dos juros compostos, cálculo do capital, do montante, da taxa e do tempo com apenas um exemplo numérico no cálculo do tempo. Os demais cálculos seguem sem exemplo numérico algum e sem a proposição de exercícios. O autor revela-se profundo conhecedor das teorias Matemáticas e sua importância, entrelaçando conteúdos e expondo a aplicabilidade dos mesmos nas questões práticas.

Outro dado, não menos importante, é que, em suas memórias, C. Ottoni observa que escreveu seus compêndios para o Primeiro Anno da Academia da Marinha. Nos Programas de Ensino do Colégio Pedro II, do ano de 1856, é possível observar seu compêndio de Álgebra indicado para o Segundo Anno. No Programa de 1858, é indicado para o Terceiro Anno, assim como no Programa de 1862. Ou seja, seu compêndio atende a níveis de ensino diferentes. A despeito de sua intenção explícita de elaborar um compêndio para o Primeiro Anno, a obra não é utilizada em turma específica, uma característica que diferencia os compêndios dos manuais didáticos atuais. Esta observação encontra respaldo em Alves para quem:

Em primeiro lugar, ele [compêndio] expressava grau limitado de divisão do trabalho didático. Quase sempre, era utilizado em diferentes séries ou anos do processo de escolarização, inclusive em diferentes níveis de ensino. Os programas do Colégio Pedro II repetiam à exaustão a expressão 'os mesmos livros do ano anterior' quando recomendavam textos de referência para os últimos anos. O compêndio apresentava-se, também, como síntese dos conhecimentos sistematizados na área 


\section{Revista HISTEDBR On-line}

Artigo

correspondente. Daí o seu volume avantajado, por mais que o autor o visse como resumo, e a despreocupação com ilustrações. Logo, a referência do compêndio era a área de conhecimento e não o ano de escolarização. Por outro lado, o fato de ser elaborado pelo professor revelava o controle por este exercido sobre o instrumento de trabalho. No caso do Colégio Pedro II, isso distanciava sua organização do trabalho didático da proposta comeniana. Nesta, o professor era mero executor das operações ligadas ao trabalho docente. O manual, instrumento especializado destinado a uma série e a uma área de conhecimento do nível de ensino, ditava essas operações. Seu autor passava a ser outro especialista que não o professor. (2012b, n. p.)

Tais peculiaridades afastam os compêndios de C. Ottoni da concepção de Comenius de manual didático que, reforçando o caráter especializado e excludente, instituiu recomendações expressas em sua Didática Magna:

I. Não se deve dar aos jovens nenhum livro, a não ser os de sua classe. [...] será muito cômodo já ter prontos, em número suficiente, todos os livros que servirão em cada classe [...].

37. Será de grande serventia também pintar nas paredes um resumo de todos os livros de cada classe, quer se trate de textos (bem resumidos), quer de ilustrações [...].

38. Agora está claro que seria muito útil ensinar uma matéria por vez em cada classe; [...]

II. Cada classe terá seus livros didáticos, que conterão e desenvolverão todo o material necessário àquela classe (para as letras, os costumes e a piedade). Enquanto os jovens estiverem na escola esses livros deverão, infalivelmente, servir de orientação até a meta desejada, sem necessidade de nenhum outro. (COMENIUS, 2011, p. 163; 216; 218 $219 ; 337$, grifos nossos).

Em relação aos compêndios adotados no Colégio Pedro II, corrobora Alves (2011) que:

Os compêndios didáticos do Colégio Pedro II disputavam, ainda, o emprego em outros níveis de ensino e numa fatia do mercado que ia além da reduzida clientela escolar. Impactavam o público externo, formado por estudiosos diletantes, e tornavam-se fontes, inclusive, para especialistas. (p. 298).

O diálogo que C. Ottoni estabelece em seus compêndios parece estar voltado aos estudiosos, intelectuais e responsáveis pela política educacional, que eram, muitas vezes, autores de textos didáticos. Conforme observa Bittencourt:

A concepção de livro didático e a sua destinação eram determinações quase exclusivas do poder político educacional, que procurava, no grupo da elite intelectual, apoio para a produção desse tipo de literatura. Tivemos assim, na geração dos iniciadores da produção didática, 
figuras próximas ao governo, escritores de obras literárias, sobretudo os principais encarregados do 'fazer científico' da época. (2004, p. 482).

A obra Elementos de Álgebra, de C. Ottoni, é parte deste contexto, em que os textos escolares eram produzidos por intelectuais interessados em instituir e consolidar, no Brasil, a formação escolar. A despeito de suas finalidades didáticas, é uma obra que denota sólida fundamentação científica, reputação ambicionada por C. Ottoni. Destinase, para além do campo educacional, aos intelectuais que se colocam na tarefa do "fazer científico" à época.

\section{CONSIDERAÇÕES FINAIS}

Ao longo deste estudo, empenhamo-nos em discutir o texto escolar como instrumento de trabalho, que assume função de mediação no interior da relação educativa, por meio da análise da obra "Elementos de Álgebra" de Cristiano Benedito Ottoni. O exemplar examinado é parte da quarta edição, "Correcta e Augmentada", publicada em 1879.

A análise da obra permitiu evidenciar que Cristiano Benedito Ottoni, ao compilar obras francesas de referência para a educação da época, ditou todo o rol de conteúdos de Álgebra secundária a ser ensinada nos colégios e liceus de todo o Brasil.

Figura irreverente, à frente do seu tempo, lutava pelos ideais Liberais. Militar, engenheiro, professor, político, seu ecletismo tornou-o conhecido e seus compêndios ícones de ensino no Colégio Pedro II.

C. Ottoni escreveu um compêndio de caráter científico, capaz de iniciar e orientar os estudantes, exigindo, contudo, a participação ativa dos professores no processo educativo.

Em relação à função assumida por este compêndio no trabalho didático, distanciase muito da proposta comeniana. Com o compêndio de C. Ottoni em mãos, o professor mantinha maior controle do trabalho e de seus instrumentos, sendo responsável, inclusive, pela elaboração dos exercícios. As discussões didáticas de "melhorias do ensino" que envolvem a oferta de conteúdo facilitado para os alunos têm início aproximadamente em 1880, quando a inclusão de exercícios nos textos escolares começa a ser exigida. Desde então, este processo de "facilitação" aprofundou-se e chegamos ao patamar de hoje, nos manuais didáticos, denominados ironicamente de "Disneylândia Pedagógica" (LINS, 1977).

Hoje os tempos são outros e novas demandas sociais e educacionais emergem à luz das condições materiais presentes. É preciso construir uma nova didática, “[...] a didática exigida pelo nosso tempo" (ALVES, 2006, p. 234), que favoreça à grande maioria trabalhadora o efetivo acesso ao conhecimento historicamente elaborado.

As discussões sobre as proposições basilares da categoria organização do trabalho didático remetem-nos à urgência de produção de uma nova didática, advinda não de iniciativas individuais, mas de uma combinação coletiva, a qual se impõe a todos os educadores que colocam a educação das massas no centro de suas aflições e objetivam, primariamente, contribuir para a democratização do conhecimento.

\section{REFERÊNCIAS}

ALVES, E. M. S. Os Compêndios das Matemáticas nos Estudos Secundários. Caderno de Pesquisa: Pensamento Educacional, Curitiba, v.3, n.6, p. 33-48, jul. - dez. 2008. 
Disponível em:

http://www.utp.br/cadernos_de_pesquisa/pdfs/cad_pesq6/3_os_compendios_cp6.pdf. Acesso em: 27 jan. 2014.

ALVES, G. L. O Pensamento Burguês no Seminário de Olinda: 1800-1836. 2. ed. Campo Grande, MS: Ed. UFMS; Campinas, SP: Autores Associados, 2001.

O Trabalho Didático na Escola Moderna - formas históricas. Campinas:

Autores Associados, 2005.

A Produção da Escola Pública Contemporânea. 4. ed. Campinas, SP:

Autores Associados, 2006.

A Centralidade do Instrumento de Trabalho na Relação Educativa: A Escola

Moderna Brasileira nos Séculos XIX e XX. In: GONÇALVES NETO, W; MIGUEL, M. E. B.; FERREIRA NETO, A. (Org.). Práticas Escolares e Processos Educativos: Currículo, Disciplinas e Instituições Escolares (Séculos XIX e XX). Vitória, ES: EDUFES, 2011, p. 279-305.

Organização do Trabalho Didático: A Questão Conceitual. Acta Scientiarum, Maringá, v. 34, n. 2, p. 169-178, jul.- dec. 2012a. Disponível em: http://periodicos.uem.br/ojs/ index.php/ActaSciEduc/article/view/17180/pdf. Acesso em: 03 jun. 2013.

Textos Escolares no Brasil. In: Anais da I Jornada do HISTEDBR/MS. "Estudos sobre Organização do Trabalho Didático"/realização HISTEDBR/MS, GEPSE. Campo Grande, MS: Ed. UFMS, 2012b, 1 CD ROM.

ALVES, G. L.; CENTENO, C. V. A Produção de Manuais Didáticos de História do Brasil: remontando ao século XIX e início do século XX. Revista Brasileira de Educação, v. 14, n. 42, p. 469-602, set./dez. 2009. Disponível em:

http://www.scielo.br/pdf/rbedu/v14 n42/v14n42a06.pdf. Acesso em: 28 maio 2013.

BELTRAME, J. Os Programas de Ensino de Matemática do Colégio Pedro II: 1827-1932. 2000. 259f. Dissertação (Mestrado em Matemática). Pontifícia Universidade Católica do Rio de Janeiro, Rio de Janeiro: 2000.

BITTENCOURT, C. M. F. Autores e editores de compêndios e livros de leitura (18101910). Educação e Pesquisa, São Paulo, v.30, n.3, p. 475-491, set./dez. 2004.

Disponível em: http://www.scielo.br/pdf/ep/v30n3/a08v30n3.pdf. Acesso em: 07 jan. 2014.

BLAKE, A.V. A. S. Diccionário Bibliográphico Brazileiro - 1883-1902. Rio de Janeiro: Imprensa Nacional, 1893. 7 v. Disponível em: http://bd.camara.gov.br/bd/handle/bdcamara/14856. Acesso em: 07 jan. 2014. O Colégio Pedro II e o Ensino Secundário no Brasil. In: BRITO, S. H. A. (Coord,). O Manual Didático como Instrumento de Trabalho nas Escolas Secundárias e Normal (1835-1945). Campo Grande, MS: 2012.

COMENIUS, J. A. Didática Magna. Aparelho crítico Marta Fattori. Tradução de Ivone Castilho Benedetti. 4. ed. São Paulo: WMF Martins Fontes, 2011. (Clássicos WMF).

Beltrame, J. Os Programas de Ensino de Matemática do Colégio Pedro II: 1827-1932. 2000. 259f. Dissertação (Mestrado em Matemática). Pontifícia Universidade Católica do Rio de Janeiro, Rio de Janeiro: 2000. 
LINS. O. Do Ideal e da Glória: Problemas Inculturais Brasileiros. 3. ed. São Paulo: Summus, 1977.

LUIZ, E. C. Os Compêndios de Cristiano Benedito Ottoni e José Adelino Serrasqueiro para o ensino de álgebra no Colégio Pedro II (1856-1928). Dissertação (Mestrado em Educação). Universidade Estadual de Mato Grosso do Sul - UEMS, Paranaíba, MS, 2013.

MIORIM, M. A. Memórias de um professor-autor de livros didáticos de matemática do século XIX: alguns apontamentos. XIII CIAEM-IACME, Recife, Brasil, 2011.

OTONI, C. B. Autobiografia. Brasília: Editora Universidade de Brasília, 1983.

OTTONI, C. B. Elementos de Álgebra. 4. ed. Correcta e Augmentada. Rio de Janeiro: Nicolau Alves e E \& H. Laemmert, 1879.

SCHUBRING, G. Análise Histórica de Livros de Matemática: Notas de Aula. Tradução: Maria Laura Magalhães Gomes. Campinas, SP: Autores Associados, 2003.

SOARES, F. S. Professores-Autores de Compêndios de Matemática no Século XIX. XIII CIAEM-IACME, Recife, Brasil, 2011.

VALENTE, W. R. Uma História Concisa da Matemática Escolar no Brasil, 17301930. 2. ed. São Paulo: Annablume: FAPESP, 2007.

Positivismo e Matemática Escolar dos Livros Didáticos no Advento da República. Cadernos de Pesquisa, nº 109, p. 201-212, março/2000.

VECHIA, A; LORENZ, K. M. (Org.). Programa de Ensino da Escola Secundária Brasileira: 1850-1951. Curitiba: Ed. Do Autor, 1998.

Os Livros Didáticos de Matemática na Escola Secundária Brasileira no Século XIX. História da Educação, ASPHE/FaE/UFPel, Pelotas, n. 15, p. 53-72, abr. 2004.

\footnotetext{
${ }^{\text {i }}$ Este trabalho é parte de pesquisa desenvolvida no interior do Programa de Mestrado em Educação da UEMS, Paranaíba. Soma-se aos estudos do GT Histedbr/MS, no esforço por analisar o papel e a função dos textos escolares no interior da organização do trabalho didático ou, mais precisamente, na relação educativa. ii Atualmente cidade do Serro, MG.

iii Condecoração destinada a premiar brasileiros e estrangeiros.

${ }^{i v}$ É a mais alta das condecorações belgas. Homenageia militares, civis e marinha mercante. É atribuída por atos de bravura em combate ou por serviços distintos prestados em prol da nação belga.

v Conselho de Instrução Pública. Lagrange era o único matemático nesse Conseil.

vi Theophilo Benedicto Ottoni (1807-1869) - político mineiro e militante republicano. Foi deputado provincial por Minas Gerais, deputado geral e senador do Império do Brasil entre 1864 e 1869. Era irmão, mais velho, de Cristiano Benedito Ottoni.

vii OTTONI, C. B. 1852. Elementos de Álgebra. $1^{\mathrm{a}}$ edição. Rio de Janeiro: Eduardo \& Henrique Laemmert. Blake (1893) informa que a última edição, a quinta, é de 1882.
}

Recebido: fevereiro-15 Aprovado: fevereiro-15 